\title{
Homenaje al profesor antropólogo Humberto Rodríguez Pastor
}

| Recibido: 04.07.2019

Aprobado: 08.07.2019

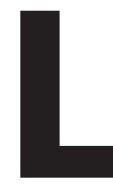

a Semana de Antropología, organizada por la Escuela Profesional de Antropología y el Centro de Estudiantes de Antropología (CEAN) se realizó entre los días 10 al 13 de junio, y el miércoles 12 de junio se ofreció un homenaje al profesor Humberto Rodríguez Pastor, quien actualmente está en la condición de jubilado. El sustento del homenaje lo hizo el profesor Sabino Arroyo quien recordó la prolongada presencia, durante tres décadas como catedrático del homenajeado, su notable producción de libros mayormente centrados en minorías étnicas no nativas así como en antropología de la alimentación y su disposición de trabajar en organizaciones académicas. Lo que sigue a continuación son las exposiciones que ofrecieron la antropóloga e historiadora Rebeca Carrasco Atachao, el Dr. Luis Alberto Suárez Rojas, docente de la Escuela de Antropología, y por último las palabras del doctor Humberto Rodríguez.

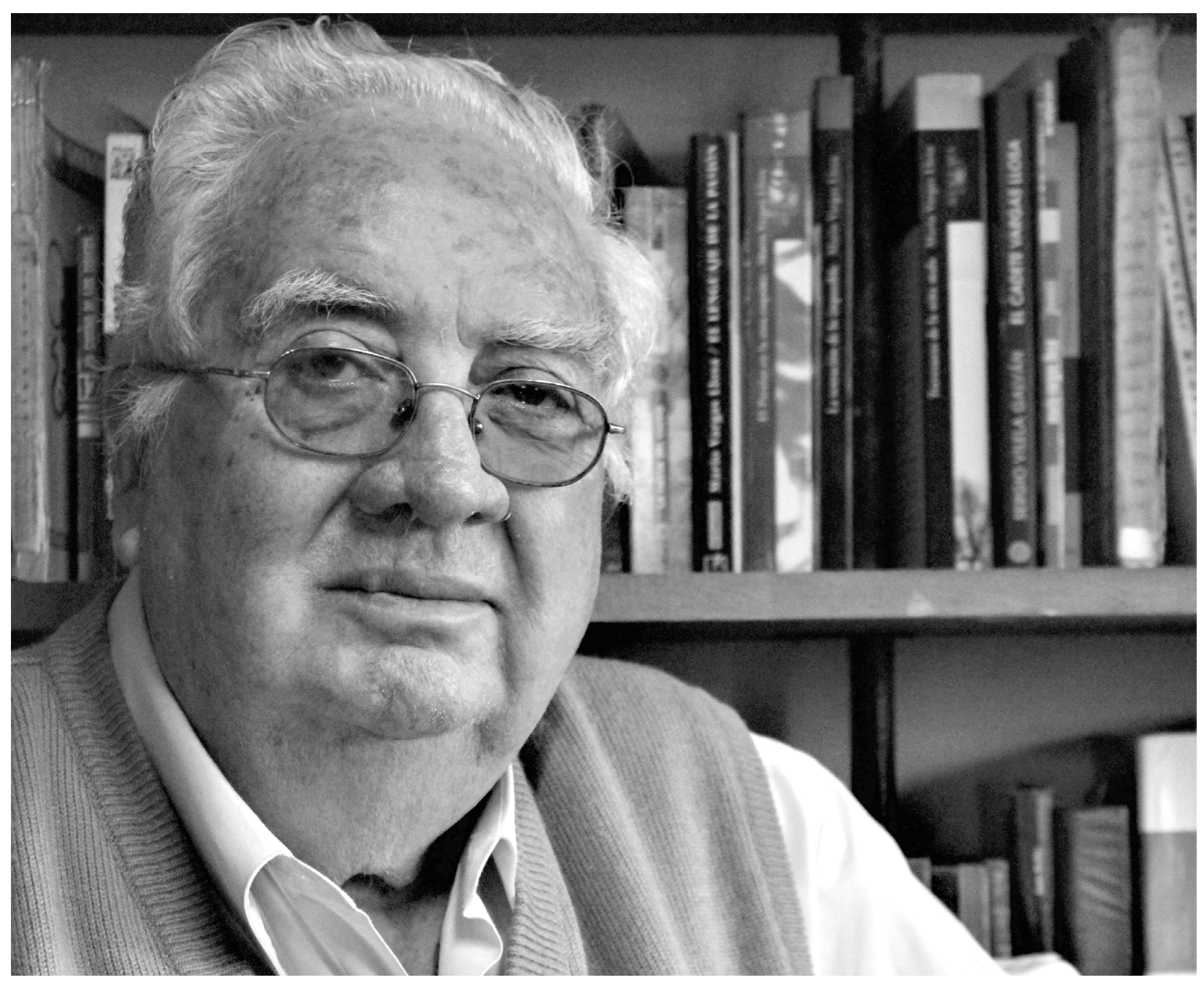





\section{Homenaje a Tito}

\section{Rebeca Carrasco Atachao}

$\int^{2}$ onozco a Humberto Rodríguez Pastor a quien llamamos Tito hace más de veinte años. A lo largo de este tiempo hemos pasado de la relación alumno-maestro a la de colaborador-colega y por eso surgió una gran y perdurable amistad. Que de mi parte es llena de admiración, cariño y respeto.

Tal vez están esperando que haga una reseña de sus logros académicos, por demás conocidos, o de su labor como investigador y la valiosa contribución de sus estudios sobre minorías étnicas en el Perú o como impulsor del 1 er Congreso Nacional e Investigaciones en Antropología el año 1985, etc.

Para mí es más importante que este auditorio conozca cómo es Tito: el docente que está siempre dispuesto a incentivar a sus alumnos en la investigación; el consejero que siempre abre su casa, su biblioteca y su familia; el amigo que siempre está dispuesto a escuchar y ayudar a quien lo necesite; el gran ser humano que no teme compartir con sus alumnos y con quien esté interesado en leer, revisar y utilizar la valiosa información que recabó en tantos archivos a lo largos de tantas décadas como investigador y que guarda «no celosamente» en su biblioteca.

Somos toda una generación que hemos tenido la oportunidad compartir con él gratas experiencias. Es tan difícil encontrar una persona como Humberto a que te encamine de mil formas, y no solo en las aulas a sus alumnos sino a quien recurre a él por diversas razones.

Y cómo no referirme a la vez que percibiendo mi interés por asistir a un congreso de estudiante de antropología, y no disponer de los medios económicos para hacerlo, me dijo «no te preocupes, te voy a pagar por adelantado porque me vas ayudar en revisar en los archivos». Me quedé asombrada. Y no se trata del dinero sino del noble gesto de ayudarme, de confiar así por así, en mí. Este episodio marcó el inicio del sinfín de viajes que emprendimos juntos por diversas regiones del Perú. No importaba la situación como encontráramos los documentos ni las condiciones en las cuales estaban los archivos, hacíamos el trabajo de recabar la información simplemente porque había despertado en mí como a otros compañeros que te ayudaban esa fascinación por hurgar en los cúmulos de papeles antiguos y descubrir aquello que los años habían dejado en el olvido.

En mi experiencia personal reconozco que Humberto Rodríguez fue quien me encaminó no solo en el tema de los inmigrantes chinos sino en hurgar en los archivos, cuando hace varias décadas atrás, siendo universitaria me llevó a revisar diversos archivos por diversas partes del Perú. Y, durante esas jornadas, cuando un día era desalentador — por no encontrar información alguna- me decía: "no te preocupen sino encuentran nada, no hay problema, ya te tocará archivos más afortunados». Quisiera agregar algo más, parte de todo este material no solo archivístico que recabamos junto con otros compañeros antropólogos e historiadores, me lo cedió como insumo para realizar mi tesis; a su vez asumió, junto a mi asesor formal, la titánica tarea de leer mis borradores, que fueron muchos. Siempre con esa nobleza que lo caracteriza me brindó sus apreciaciones y críticas. Así de desprendido es Tito si de ayudar se trata.

Años más tarde, emprendimos otros proyectos. Por ejemplo, junto a un grupo de egresados de esta casa de estudios [San Marcos] de diversas especialidades, formamos TESA: Taller de Estudios de Antropología de la Alimentación. Qué enriquecedoras fueron nuestras reuniones en las que discutíamos temas de común interés, en conversaciones con invitados, en armar los sílabos en los cursos que dictábamos juntos, etc.

No nos contentábamos con tener que dictar un curso. Por ejemplo, en la Escuela de Nutrición su clásica pregunta era: ¿qué podemos ofrecer a los estudiantes de nutrición desde la antropología? ¿Cómo puede ser útil la antropología a un estudiante de nu- 


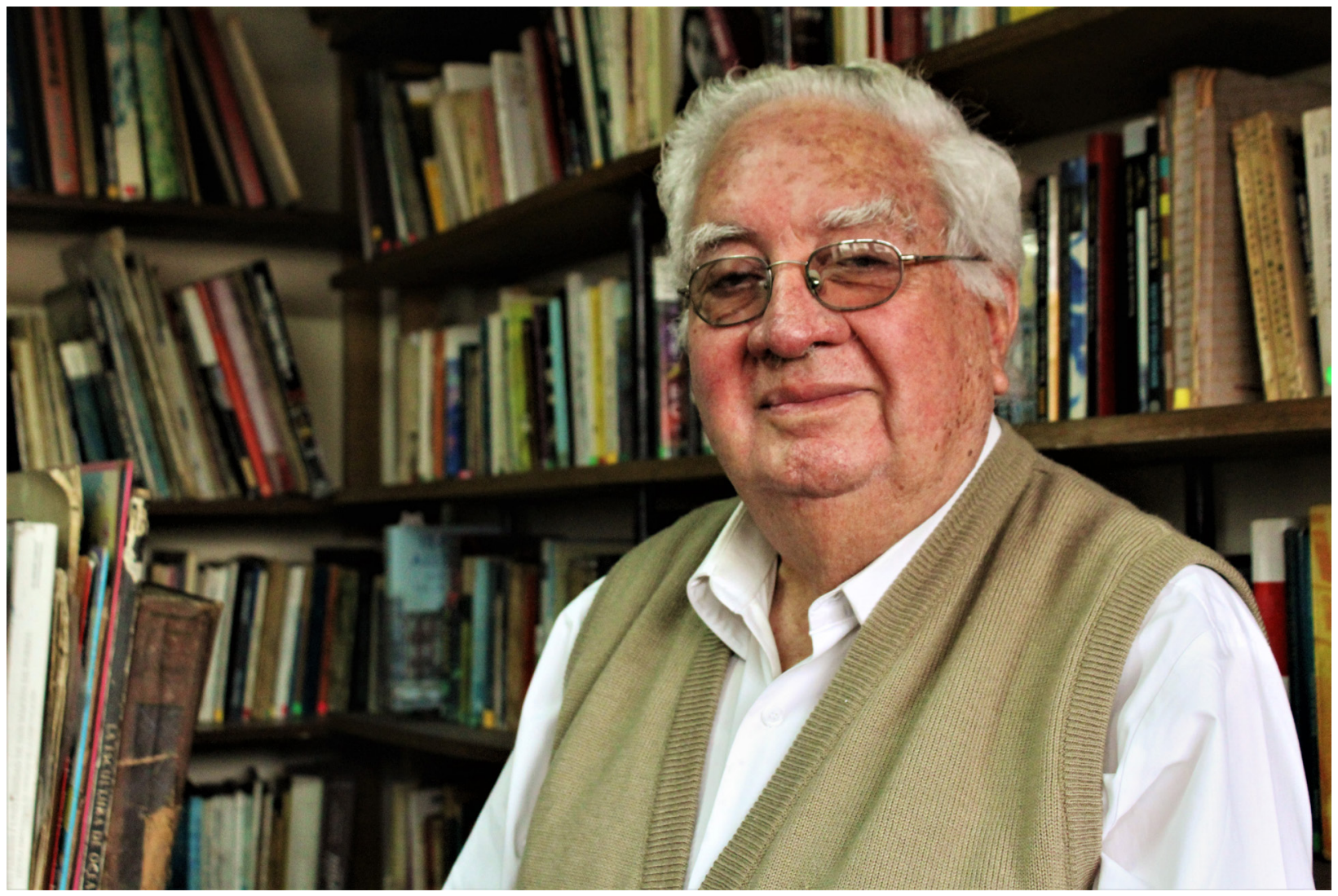

trición? Así nació nuestro interés por la antropología de la alimentación y sobre todo por brindar en las aulas cursos que estén diseñados para estudiantes de cierta especialidad.

Los integrantes de TESA tomamos rumbos lejanos a las aulas, sin embargo esta distancia no ha sino un alejamiento con Tito, pues sin temor a equivocarme siempre está presente. Actualmente, hemos formado un nuevo grupo, esta vez menos académico y apelando a la tecnología tenemos un grupo en WhatsApp que se autodenomina "Los Comelones», pues nuestros encuentros se remiten a tours gastronómicos por distintas propuestas culinarias preferentemente no peruanas y que ofrecen restaurantes en Lima. Y aunque siempre decimos está prohibido hablar de política, es inevitable. También lo es encontrar nuestros espacios para compartir nuevas experiencias. En esas reuniones hay proyectos e inquietudes por compartir pues hay amistad sincera.

Bueno estoy casi segura que este tipo de gestos describen a Tito tal como es, una persona noble y consecuente con sus ideales, que da el ejemplo de cómo ser solidario. No he querido describir al Tito investigador porque sus publicaciones hablan por sí mismas. He querido mostrar al Tito de la vida cotidiana, a partir de experiencias que he tenido la fortuna de compartir con él; mi intención ha sido describir al Tito amigo, compañero y porque no decirlo del amigo que goza con las alegrías de los otros y se entristece con las penas de los demás, aquel que se me muestra solidario con todos y por todos.

No puedo dejar de mencionar lo agradecida que estoy por haberme brindado su amistad, no importa si me llama a las seis de la mañana para decirme que me envió un e-mail y que debo responder en el acto. Porque a pesar del tiempo encontramos forma de seguir acumulando excelentes recuerdos. Porque aunque son otros tiempos y otros contextos. Le ofrezco en público estas últimas palabras que quisiera gritarlas: tú eres y serás la persona a la cual le tengo una gran admiración y un enorme cariño, porque, mi Tito querido, eres mi mejor amigo. 


\section{Una concepción de las ciencias sociales sin límites}

\section{Luis Alberto Suárez Rojas}

«Mi concepción de ver las ciencias sociales no tiene limites» ${ }^{1}$

1a a antropología es una disciplina que floreció en la Universidad Nacional Mayor de San Marcos a finales de la primera mitad del siglo xx. Para ser exactos, en 1946. Y sucedió gracias a la Ley Universitaria a partir de la cual se creó el Instituto de Etnología y Arqueología en la Facultad de Letras de la cual salían profesionales en etnología (actualmente se usa antropología) y arqueología. En ese mismo año, Humberto Rodríguez Pastor (HRP en lo sucesivo) dejaba la infancia con apenas 10 años y era el tercero de cuadro hermanos. Su padre fue un militar de rango y por eso su familia fue itinerante, viviendo por etapas en ciudades como Iquitos, Arequipa, Piura, Lambayeque, Lima y Huancayo. Los especialistas dicen que algunos sucesos en la infancia marcan por siempre nuestro destino, ese parece ser el de la persona del cual hablaremos.

Así, Humberto Rodríguez Pastor recuerda en una entrevista que a la edad de ocho años un carro lo atropelló y se rompió la pierna. Ese desafortunado suceso provocó un paréntesis de casi un año que le cambió la vida y lo acercó a la lectura, así, recuerda: "pasé mucho tiempo en el Hospital Goyeneche de Arequipa y es ahí cuando empecé a leer libros de guerra y la revista Selecciones de Readerss Digest's» (Rodriguez, 2018). Ya en Lima, su infancia transcurrió próxima a la plaza Dos de Mayo. Ese fue su barrio, el escenario de las correrías, la patota $y$, como era frecuente en muchos otros barrios, de la presencia china y también japonesa, lo cual atrajo su atención seguramente sin percibirlo pero guardándolo en su hondón. Como

1 Humberto Rodríguez Pastor, Caretas, 20 dic 2018. bien recuerda «en mi barrio donde crecí — cerca de la plaza Dos de Mayo- hubo un chino de la esquina, se llamaba Enrique, cuyo hijo era parte de nuestra patota, tuve y tengo inmensa curiosidad por la gente que vino del Asia» (Rodríguez, 2018). Además, dos de sus mejores amigos en Piura el ańo 1951 fueron hijos de chinos, Gerardo Yap Huamán y Mario Wong Saavedra. A ellos se sumó cuando estuvo de cadete en el Colegio Militar Leoncio Prado (19521854), Augusto Murayama Nagahara, un nisei que con él estaba en la úndecima sección de la novena promoción leonciopradina, sección de los de menor tamaño que ni siquiera habían cambiado de voz. En ese colegio obtuvo lo mejor de su estancia castrense: orden, disciplina, trabajo en equipo, entre otros valores esenciales para el posterior desarrollo de su talento y vocación. Tal como sucedería con otros ilustres leonciopradinos, por ejemplo, el escritor Manuel Scorza y el nobel Mario Vargas Llosa. De esta experiencia HRP publicaría muchos años después su libro titulado La Novena en Décimas (2006) en el cual narra en décimas las peripecias de los cadetes de la IX Promoción «Mariscal Ramón Castilla».

Sus inicios universitarios se realizan en un ambiente político de cambios y tensiones a nivel nacional e internacional. Los ańos sesenta empezaron un año antes en 1959 con la revolución cubana castrista, con la crisis de los misiles en 1962, el asesinato de John F. Kennedy en Dallas (1963), la guerra de Vietnam (1964), mucho de ellos acentuó las fuertes tensiones entre el bloque comunista liderado por la URSS y el de los Estados Unidos. Durante esta década en el país emergieron movimientos guerrilleros, sindicales, muy agresivos y tomas de tierras en el campo y en la ciudad donde surgieron las barriadas. Hugo Blanco lideró acciones insurgentes en el valle de La Convención en Cusco, el general Ricardo 
Pérez Godoy da un golpe de Estado contra el presidente Manuel Prado, y en 1963, Fernando Belaunde ganó las elecciones hasta 1968, cuando se produce el golpe militar del general Juan Velasco Alvarado, dando paso al proceso de reforma agraria y otras transformaciones.

En ese flujo de eventos, HRP realizó su pregrado, primero en Estudios Generales de la Universidad Católica de Lima (1958-1959), luego en la Universidad Nacional Mayor de San Marcos durante los años 1960-1962 (UNMSM) y finalmente, entre los años de 1963-1965 en el Institute des Hautes Études de l'Amerique Latine y en la VIéme Section de la Universidad de París. Fue alumno de destacados historiadores como Raúl Porras Barrenechea, provocándole un fuerte interés tras leer las crónicas de Pedro Cieza de León y la de Fernando de Montesinos; además, ya en San Marcos, tuvo docentes como Luis Valcárcel, José María Arguedas, José Matos Mar y Jean Vellard, quienes alimentaron su inclinación por la etnología y la investigación. En ese contexto ha señalado: «Es aquí cuando el escritor José María Arguedas me dejó claro que el racismo era una construcción sin base» (...) «Me inspiró en esta ciencia y a escribir mi veintena de libros» (Rodríguez, 2018). Para la generación del 60, como para HRP, Arguedas dejó una huella importante, pues de él escuchaba el sustento sólido que explicaba la realidad del mundo del indio peruano. A eso se suma la repercusión de antropólogos extranjeros como François Bourricaud, Juan Comas, Eduardo Lanning y John Murra, que contaba en esos momentos con la importante dirección de la escuela de Etnología de parte de José Matos Mar cuya concepción inicial fue de Luis E. Valcárcel.

Gracias a un texto preparado por el propio antropólogo en el 2004, tenemos su testimonio sobre sus años sanmarquinos. En su «Mi ego historia como estudiante sanmarquino» (Rodríguez, 2004) apunta que las lecturas recurrentes eran los trabajos de Melville Herskovitz, Ralph Linton, Clyde Kluckhohn, Margaret Mead y Ruth Benedict; además de los textos de Oscar Lewis, con obras como Antropología de la pobreza (1959).

Otro aspecto igualmente inscrito en su ego-historia-sanmarquina (Rodríguez, 2014) es la importancia del trabajo de campo. Sus años en el Instituto de Etnología y Arqueología fueron años sin tiempo para el descanso; las vacaciones fueron cambiadas por prácticas de campo. Entre ellas se cuentan la experiencia de Rodríguez en el valle Lurín, donde amplió una biografía de un viejo comunero Eufemio Sabá Rivas, luego en Huaylas (Ancash) que permitió visitar el famoso proyecto Vicos en Ancash, luego tuvo prácticas en Chinchero en Cusco. Al siguiente año, en el verano de 1962 fue parte del laboratorio del valle de Chancay, luego en 1963 realizó prácticas durante casi tres meses en Bolivia, en la Marca Llica en la provincia de Potosí al lado de los salares de Uyuni y Coipasa, en este último caso alternando con profesores bolivianos.

Estas experiencias fueron inigualables y tuvieron la potencia de enriquecer su formación antropológica. No hay libro de texto o de cabecera que reemplace el vínculo directo sobre el que se funda la propia experiencia antropológica. Nuestra disciplina tendrá la formalidad de textos, monografías y teorías, pero la antropología es sobre todo un acontecimiento del encuentro dialógico. En nuestra opinión, un aspecto sustancial es que el Instituto de Etnología, con sus aciertos y dificultades, logró en ese momento formar universitarios y profesionales que conocían la realidad nacional e internacional, no de oídas, sino gracias a haberse ensuciado los zapatos, reafirmando el clásico «yo estuve ahí». A esto se suma, la posibilidad de alternar en San Marcos con personajes intelectuales como José Matos Mar, José María Arguedas, Luis E. Valcárcel, entre otros.

Su estancia en Francia constituye un hecho relevante. Cuando él llegó, Pablo Macera había regresado al Perú un año antes. Ahí se encontró con antiguos amigos, como Federico (Fico) Camino y José Portugal Mendoza, igualmente antropólogo sanmarquino. Lo último que hizo en París junto a otros fue la toma de posición con respecto a las guerrillas, asunto que generó un revuelo mediático. Esa toma de posición se firmó el 22 de julio del 1965, y suscribieron HRP, Vargas Llosa, Hugo Neira, Federico Camino, Ruiz Rosas y Julio Ramón Ribeyro. En el escenario parisino conoció casi de pasada a Manuel Scorza y a Víctor Raúl Haya. Además, tuvo la oportunidad de alternar con dos personalidades que luego rivalizaron y marcaron parte de la historia política de país, me refiero a Mario Vargas Llosa y Alberto Fujimori, a quien conoció en París mientras estaba de paso donde iba a seguir en Bélgica cursos de matemática, incluso algunas fotos así lo testimonian. Finalmente, disfrutó 


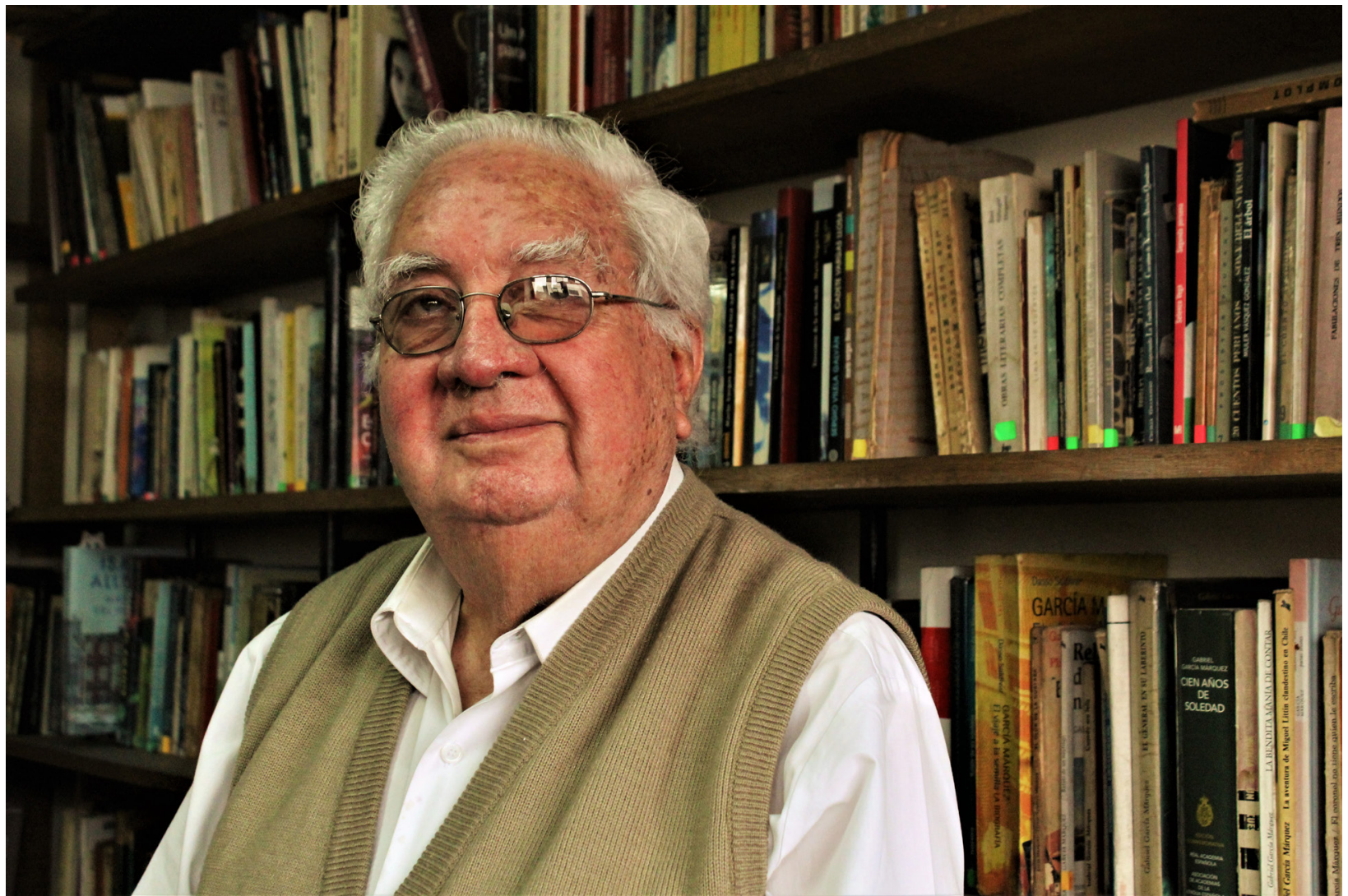

un célebre concierto en 1965 de The Beatles². A su regreso de Francia, en 1967, obtuvo su Bachiller en Etnología y Arqueología por la UNMSM.

De su recorrido sanmarquino, HRP destaca que ahí encontró la vocación por hacer ciencia, abraza el ideal del intelectual comprometido, donde el quehacer intelectual y académico no debe estar reñido con las potencialidades transformativas y revolucionarias. Esto fue un aspecto angular en su posicionamiento y orientación. Esto se explica en parte por el ambiente del Instituto impregnado por las ideas de Valcárcel que se orientaban a pensar el Perú a partir de la posibilidad de estimular cambios. Por otra parte, y para la época, el novedoso proyecto Vicos, el cual fue un referente de antropología aplicada. A esto se suma la ebullición del ambiente político e ideológico de la época. HRP tuvo claro que en San Marcos aprendió que el trabajo antropológico es a favor de los sectores populares y que sus esfuerzos deberían ge-

2 Debo señalar mi total gratitud y complicidad a su nieto, Luis Rodríguez Pastor, quien me confió algunos datos biográficos de HRP. Para él y su familia mi gratitud. nerar soluciones concretas para las grandes mayorías postergadas. Quizá la primera sentencia de su propio decálogo sería: «No creo en una antropología aséptica ni indiferente» (2004: 271, ) como lo señala explícitamente en su ego-historia-sanmarquina. Así, en el ambiente de las aulas fue donde asimiló la aspiración igualitaria entre orígenes, colores, clases sociales, y diferencias étnicas, etc.

Luego vendrían otros desafíos. Desde 1971 y cerca de una década estuvo a cargo de la dirección del Archivo Agrario donde con todo un equipo de gente reunió los documentos de las haciendas afectadas por la Reforma Agraria llevada a cabo por la Junta Militar del general Velasco Alvarado. Este valioso acervo documentario tuvo un Comité Técnico integrado por intelectuales como Manuel Burga Díaz, Ernesto Yepes del Castillo y el recordado Alberto Flores Galindo (Del Águila, 2017). César Gutiérrez Muñoz (2017) ha señalado con justa razón que en la historia de la archivística hay momentos cumbre y este fue uno de ellos, por eso señala: "Fue un gran esfuerzo archivístico como no ha habido otro» (Gutiérrez, 
2017: 25), refiriendo a la titánica tarea de HRP en la dirección de esta institución. En esos años, HRP como director y con la ayuda de colaboradores, recogió y salvó los documentos de las haciendas expropiadas por la Reforma Agraria (1969). Entre otros investigadores, Michael Gonzales, quien analizó desde una perspectiva histórica una hacienda azucarera, da su testimonio sobre el archivo agrario: «El archivo tenía el ambiente de un archivo popular, lo que reflejaba el compañerismo de Humberto Rodríguez Pastor, su director, quien brindaba a todos por igual acceso a la documentación» (Gonzales, 2016: 17). En el contexto del Archivo Agrario, también conoció muy de cerca a intelectuales como Eric Hobsbawm y Ruggiero Romano y otros más que se acercaban por el prestigio que iba adquiriendo ese repositorio de documentos de empresas agrícolas.

HRP no es solo un académico prolífico, acucioso y comprometido, goza además de cualidades ejecutivas para la dirección y la gestión. Estas cualidades muy difícilmente se encuentran juntas. Por esa razón, desde la década de 1980, no fue raro que fuera parte del Consejo Nacional de Ciencia y Tecnología, como director de la Dirección de Ciencias Sociales del CONCYTEC (1982-2007). Desde esa posición logró algún apoyo económico y sobre todo con dinero del Erario Público pudo impulsar la investigación de diversos colegas y actividades académicas. Destaca su esfuerzo por sacar adelante el $1 .^{\circ}$ Congreso Nacional de Investigaciones en Antropología en noviembre de 1985. Al respecto, el año 2008, Carlos Iván Degregori subrayó «desde intentos personales, solitarios y a contracorriente como el de Humberto Rodríguez, que se puso el equipo al hombro en los peores momentos de la década de 1980, organizó desde CONCYTEC el 1. ${ }^{\circ}$ Congreso de Antropología y contribuyó a que se materializaran los siguientes». (Degregori, 2008: 24).

Desde sus años universitarios el compromiso político fue gravitante, pero osciló de la política partidaria a la política de la reivindicación de las minorías, apoyando causas como la lucha contra el racismo y la revalorización de la afrodescendencia en el Perú. Durante varias décadas sus intervenciones públicas fueron la prueba de su resistencia, constancia, compromiso con la justicia social. Su voz nunca cesó de hablar fuerte y claro, invitando a su generación y a las siguientes generaciones a repensar el Perú desde los dramas de la injusticia colonial y republicana hasta reconocer el aporte fluido de las minorías étnicas en la vida cultural y política de la nación.

HRP fue parte de la generación de oro de la Antropología y las Ciencias Sociales. Sus contribuciones son en diversos niveles y se pueden reconocer innumerables aportes. En el campo del estudio sobre las poblaciones afro, las migraciones chinas y japonesas en el siglo XIX y Xx, y en el campo de la antropología de la alimentación. Su producción abarca casi cuarenta años de actividad intelectual. Para citar podría considerar trabajos como «Caqui: Estudio de una hacienda costeña (1969)», "Los trabajadores chinos culíes en el Perú. Artículos históricos (1977)», "Chinos culíes: Bibliografía y fuentes, documentos y ensayos» (1984), "Hijos del Celeste Imperio en el Perú (1850-1900) (1989)», "José Carlos Mariátegui la Chira: Familia e infancia» (1995), "Herederos del Dragón» (2000), «La Novena en décimas» (2006), "De tamales y tamaleros: Tres historias de vida" (2006), «Negritud. Resistencia y existencia» (2008), "La vida en el entorno del tamal peruano" (2007), El ají peruano en sus regiones y pueblos (2014), Ají peruano. Historia, cultura, sociedad y gastronomía (2016), «Chinos en la sociedad peruana. 1850-2000» (2017), El peón y empresario Nikumatsu Okada y la comunidad japonesa del valle de Chancay 19001950 (2018), entre otros títulos.

Con justa razón, en 1989 ganó el «Premio Concytec Jorge Basadre», correspondiente a la tarea de Historia del Perú Republicano por la obra «Hijos del Celeste Imperio en el Perú» (1850-1900).

No hay duda, su trabajo ha ofrecido una línea de resistencia a las modas antropológicas y se ha anclado en su propio proyecto y política de revalorización que consiste en analizar desde una perspectiva histórica y cultural el devenir de las minorías étnicas en el país y el drama de la «integración» en una nación aun escindida y fracturada.

Desde otra perspectiva, podríamos sugerir un balance, en el sentido que sus contribuciones han enseńado a muchas generaciones las potencialidades de juntar el trabajo archivístico con la percepción antropológica, así, la historia no solo constituye una sucesión de eventos ni largas estructuras, la historia desde esta visión nos acerca a la vida misma, desde lo micro hasta lo macro. Otra contribución de su trabajo es de orden metodológico, nos referimos al uso de la «historia de vida». Lo que nos ha mostrado nos deja 
muy claro su potencial, pues, a través de la entrevista a profundidad y al arte de la conversación se construyen narrativas que dan cuenta tanto de la historia personal, biográfica, como también colectiva. Las historias de vida no son solo una ventana abierta a la vida social, es la posibilidad mixta de escribir sobre aquellos que la sociedad se empeńa en invisibilizar. Y ese es el gran aporte del profesor Humberto: está lejos de las modas académicas y más cerca del compromiso social y transformativo.

Debo dar fe y testimonio como alumno de Tito que al principio me disgustó su distancia de la teoría y de esos aspectos muy formales de la antropología. Quizá mi propio atrevimiento y soberbia juvenil no me dejaban dar cuenta de lo importante. $\mathrm{Al}$ inicio era decepcionante. Eso me recuerda al film «Karate Kid» (1984), donde Daniel Larusso pide al señor Miyagui que le comparta el «secreto más profundo» del karate japonés, y ante eso el señor Miyagui solo responde dibujando círculos sobre el piso «encerar y pulir». De manera análoga, HRP en etnografía comparada, solo me pedía «escribe sobre tu bisabuelo chino y busca los archivos» y "luego ve a hacer la biografía de la señora de los tamales». Todo eso me sonaba a «encerar y pulir». Finalmente, tras derrumbarse mi propia soberbia juvenil, cambié mi óptica y ahora parto de la idea de que la antropología se construye sobre la base de la experiencia del sujeto, su voz, sus rastros concretos, sus avatares, sus victorias, sus sufrimientos y sus silencios. Ahí descubrí que el secreto no está en las maravillosas filigranas y juegos retóricos de la teoría sino en lo que podemos decir desde y para los sujetos que viven el lado perverso de la historia. Esa es la lección que más atesoro de Humberto Rodríguez Pastor.

Así, su trabajo constituye un ejercicio de dar voz y ofrecer la "chance», la oportunidad para que todas esas vidas refundidas en los archivos hagan un verdadero cierre, dando cuenta de manera organizada y sistemática de sus vivencias, sus reclamos, sus reivindicaciones y sus infortunios. Gracias a HRP, esas familias africanas y asiáticas podrán seguir escribiendo su historia sobre cómo se ganaron a pulso un lugar en esta tierra. Una historia que en este momento es compartida.

En 2017 nos presentó su opus magnun Chinos en la sociedad peruana (1850-2000). Presencia, influencia y alcances. Esta investigación destaca ampliamente por su ejercicio de pensar el devenir de la diversidad cultural a partir de la migración china y las relaciones interétnicas. Sobre todo, es un valioso aporte, porque parte del «sujeto» para reubicarlo en una compleja trama de relaciones sistémicas y transformaciones capitalistas en el sistema-mundo y en nuestro ámbito nacional. Su trabajo es ejemplar, pues, construye un trabajo fino, consistente, copioso en detalles, logrando conjugar la mirada estructural, sistémica, en diálogo con las representaciones de la sociedad nacional y los universos de sentido y significado de los sujetos considerando sus marcos culturales. Por otra parte, enfatiza la relación entre etnicidad y el territorio como trama de sentido y cargado de historia. En resumen, toda la investigación constituye una brillante aproximación a la larga duración y a los procesos de construcción de identidad, al tiempo que comprende los reveses de una sociedad que antaño los relegó a vivir en las condiciones de semi-esclavitud y que años más tarde los reivindicaría como uno de los más importantes contribuyentes a los más valorados productos culturales de nuestra sociedad peruana como es la gastronomía.

Otro aspecto que no quisiera dejar escapar es su actividad docente y su quehacer. Ahí me hace recordar las reflexiones sobre el eros pedagógico. HRP fue uno de los primeros en desarrollar eso que los pedagogos llamaron aprendizajes significativos, nunca le interesó que sus alumnos tengan la cara enterrada en los libros, le interesó guiar a sus alumnos, convencerlos de la importancia de tener experiencias directas, desarrollar el arte de la entrevista, armar genealogías, dejarse impactar por el acontecimiento del encuentro con ese nosotros diverso. Sus clases fueron siempre diálogos abiertos, su técnica socrática se combinaba con sus tomas de posicionamiento. Hoy, las actuales tendencias de la biopedagogía hablan de la mediación pedagógica, entendida como el proceso de acompañamiento del aprendizaje y revisión de contenidos, que busca que el estudiante aspire a darle sentido para su vida. Esta es una nueva tendencia. Sin embargo, a lo largo de sus más de 30 ańos enseńando HRP ya lo había puesto en práctica.

A finales del 2018, recibió por parte del Ministerio de Cultura el «Premio Nacional de Cultura», por su alta contribución a la nación. HRP ha reconocido desde su temprana juventud la importancia de que lo que hagamos deje una huella duradera y útil para los demás. Su trabajo ha sido a lo largo de estos años 
construido con inteligencia, creatividad y corazón. Esto nos recordará siempre que nuestra labor se posiciona en favor de quienes están atrapados en las estructuras de la dominación, la injusticia y la desigualdad. Solo queda decir, gracias por compartir una vida ejemplar, de convicción y lucha. Como bien declaró en diciembre del 2018: «El dolor de nuestros informantes nos vuelve (a los antropólogos) inevitablemente rebeldes y nos pone de lado de los pobres del mundo, los esclavos sin pan y la gente sin historia» (Rodríguez, 2018).

Ciudad Universitaria, 12 de junio de 2019

\section{Bibliografía}

Caretas (2018). «Prodigio Cultural. Entrevista a Humberto Rodríguez Pastor». Edición 2570, del jueves, 20 de diciembre de 2018.

Degregori, Carlos Iván (2008). ¿Cómo despertar a la Bella Durmiente?: por una antropología para comprender un país escindido. En: Alejandro Diez (coord) La Antropología ante el Perú de hoy: balances regionales y antropologías latinoamericanas. Lima: PUCP. CISEPA, 280 pp.

Gutiérrez Muñoz, César (2017). El agradecido aplauso a Humberto Rodríguez Pastor. En: Boletin Archivistica PUCP. Año XV, N ${ }^{\circ} 175$, abril, 2017.

La República (2018). "Humberto Rodríguez Pastor, el investigador de las minorías». Edición del 24 noviembre del 2018.

Rodríguez Pastor, Humberto (2004). Mi egohistoria como estudiante de antropología. En: Revista de Antropología, Facultad de Ciencias Sociales. E.A.P. de Antropología, UNMSM, Lima.

Rodríguez Pastor, Humberto (2006). La Novena en Décimas. Lima, Perú.

Rodríguez Pastor, Humberto (noviembre 2018). Discurso de Aceptación del «Premio Nacional de Cultura por Trayectoria», otorgado por el Ministerio de Cultura, Lima. 


\section{Mi historia sanmarquina 0 San Marcos la culpable}

Humberto Rodríguez Pastor

E studié antropología en San Marcos entre los años 1960 y 1962 . Antes de ello tuve que seguir dos años en la Facultad de Letras de la Pontificia Universidad Católica del Perú donde aún no se ofrecía esta profesión. A continuación siempre estuve cerca de mi universidad de San Marcos donde fui profesor hasta hace dos años que me jubilaron.

Ahora que se cumplen 468 años de existencia de la Decana les cuento lo que para mí fue esta universidad y la antropología de entonces y lo que significó para mí en el resto de mi existencia.

En los años en que estuve en San Marcos encontré un conveniente contexto para definir mi vocación como investigador $\mathrm{y}$, por tanto, decidirme para siempre por la investigación científica. Asimilé y fue conclusión mía que hacer ciencia es también hacer revolución y lo es más si se hace desde las Ciencias Sociales.

Tuve como profesores a Luis E. Valcárcel, José María Arguedas, Jorge Muelle, Jean Vellard y a José Matos Mar. Es buen momento para reiterar mi agradecimiento a todos ellos en cualquier parte que se encuentren por sus enseñanzas y por la transmisión de múltiples inquietudes académicas. Valcárcel estaba por los 70 años y su lugar donde nos dio clases fue el Museo de la Cultura, ese Museo era de nuestro cariño. Arguedas lo reemplazó en el curso de introducción a la etnología y nos sugería que vayamos a escuchar en la carpa de la avenida Bolívar al Jilguero del Huascarán y él mismo, por supuesto que fuera de aulas, entonaba la hermosa pieza andina wifalita wifala que ahora es Patrimonio Cultural de la Nación; Muelle era un arqueólogo erudito en todo, supimos de él desde la importancia y exquisitez del anticucho hasta de las especiales columnas de Chavín; Matos nos convocaba para que lo acompañemos en dictar un curso o sin contemplaciones nos empujaba al tra- bajo de campo así como ciertos padres de familia que arrojan a sus hijos a las piscinas para que solos se atrevan a nadar; Vellard me enseñó que en el Perú había una selva amazónica con gran variedad de chunchos, como despectivamente los llamábamos por entonces los citadinos, que usaban flechas de puntas variadas de usos variados, de él supimos de los uros y los chipayas de la altipampa.

En San Marcos aprendí que la profesión de antropólogo debe tener a su vez una orientación a favor de los sectores populares. No entiendo ni teoría ni práctica antropológicas que no se alineen a la solución de los problemas de la mayoría de peruanos que son pobres, maltratados, engañados permanentemente, explotados, desatendidos, utilizados en todas las elecciones y en la que habrá el 2021 ańo del bicentenario.

No creo en una antropología aséptica ni indiferente ni químicamente pura, debe hacerse con el corazón y con algo de nuestros sesos, en la búsqueda de hacer teoría para la puesta en práctica.

Este mismo aprendizaje y mil inquietudes socialambientales sanmarquinas me condujeron a asumir una militancia política que perduró durante dos décadas y cuya orientación central no la he perdido jamás. Estoy seguro que mi corazón está a la izquierda y que mi sangre es roja. Y sigo manteniendo la idea que ser de izquierda es pensar en esa gente peruana sin historia, esos pobres sin pan. Y que en este mundo de los subalternos hay un potencial o magma humano por el que hay que luchar para que emerja como lava de un volcán y aparezca todo un nuevo universo.

En San Marcos tuve un ambiente en el que se inculcaba una relación igualitaria entre gente de muy distintos orígenes y colores, pobres y ricos, blancos, cholos o negros. Las relaciones entre profesores y alumnos así era. Y esto también lo hemos vivido en el trabajo de campo y la hemos practicado con la gente 
a la que le hacíamos cienmil preguntas. Y esta relación horizontal la hice mía de por vida, tanto que ahora actúo como un militante antirracista en vez de la militancia política que hace más de veinte años la he dejado.

En San Marcos me contagié de la importancia de la vida próxima entre profesores y alumnos y, por tanto, de lo que significa la entrega y seriedad de un docente por la docencia universitaria, por la actualización permanente y por el interés por sus alumnos más allá de las aulas sin caer en las intromisiones.

En San Marcos supe de la importancia de vivir de cerca a la realidad social y cultural de cualquier lugar del Perú y que para conocerlas hay que hacerlo de muy cerca. Nada de telescopios ni de largavistas, ni celulares ni internet ni de interpósitas personas, nada de me lo contaron, lo conveniente es lo escuché y lo viví. Sigo estando seguro de que no hay que ilustrarse del comportamiento sociocultural desde la lejanía; y cuanto más tiempo se viva en un grupo humano al que no perteneces te enriqueces como antropólogo.

El trabajo de campo es tan importante en enseñanzas como lo que se escucha en las aulas. Los que estudiamos antropología en aulas sanmaquinas tuvimos de maestros a Vellard, Muelle, Arguedas, Matos, Valcárcel, etc., así como también tuvimos como catedráticos a Eufemio Sabá de Pachacámac, a Pedro Quispe Aucapuma de Chinchero, a Rosendo Maqui de la comunidad de Rumi, a Miguel Situ Rojas de Chepén y a un millón más.

La antropología que asimilé en San Marcos me mostró que al profesionalizarme no ingresaba solo a una disciplina científica, también me inscribía a un modo de vida particular. En mucho la teoría antropológica es desprejuiciadora, te da una solidez que sin dudar sabes que mil santos y mil temas sagrados no son inmutables a los que hay que adorar, pues hay otros tantos de igual importancia. Y, por favor, tengan en cuenta que no me estoy refiriendo solo a religiones, ídolos o ángeles celestiales, pienso en las apreciaciones artísticas, en el aparente mundo caótico de los valores, en las interrelaciones interpersonales de todo tipo y hasta hacia el variado aprecio a todo un bosque de crisantemos o de violetas africanas.

La antropología te enseńa a dormir donde sea, a comer lo que sea, a bailar lo que nunca creíste poder bailar, a considerar nuevos tipos de belleza y te hace reír de cosas totalmente nuevas. El trabajo de cam- po con otros antropólogos te hermana con ellos para siempre. Así me ocurrió en San Marcos en la década del 60 y en los 50 años que siguieron.

La antropología de mis años de estudiante me hizo necesario saber la importancia por igual de la historia, de la arqueología, de la sociología, y hasta de la paleoantropología africana y la paleontología andina que no dejo de buscar leer en revistas más que en libros. Y hay que tener en cuenta que nuestra profesión se engrandece cuando te aproximas a cualquier otra disciplina científica, incluso a las simpáticas matemáticas.

La antropología te obliga cuando solo tienes canas a recibir homenajes que casi parecen de despedida que no será mi caso; me quedan aún cien años por vivir y joder. Esa antropología que la llevo en mi mochila desde hace muchas décadas, no me ha podido jubilar como San Marcos lo ha hecho para lo cual me da un cartoncito que me lo otorga por mi fructífera labor académica, es casi chau, gracias Humberto Rodríguez. Y no es así y no será así. En mi barrio que es muy concurrido y donde paso más tiempo que en años anteriores sigo haciendo antropología a partir de mil chismes o datos de informantes, doy clase de la historia de Lima a los taxistas que me transportan a algún lugar, no saben que antes hubo tranvías ni que el jirón de La Unión era de ida y vuelta ni que hubo un gran policía de tráfico afro de apellido Nonone y por igual hago antropología en mi torre de marfil en el tercer piso de mi casa donde casi todos los días redacto uno o más párrafos.

Y en el mes de noviembre del año pasado me dieron el Premio Nacional de Cultura 2018 como si fuese otro chau, Humberto. De lo que dije en esa ocasión he parafraseado las siguientes líneas: casi nada de lo que he hecho ha sido de manera solitaria: si en un curso, con estudiantes o jóvenes antropólogos; si en la organización de un certamen científico, en grupo con otros de mi oficio; si en una investigación, acompañado de gente joven en la que aprendemos juntos la sabrosura de nuestros ajíes o nuestros tamales. A toda esta tantísima gente que ha estado a mi lado en el desempeño de mi antropología, le agradezco y creo que les corresponde mucho de este homenaje que me ofrecen hoy. Que viene con cariño pero no dejo de sentir que me dicen, chau Tito.

Gracias. 